\title{
Safety and Efficacy of Weekly 30,000 IU Vitamin D Supplementation as a Slower Loading Dose Administration Compared to a Daily Maintenance Schedule in Deficient Patients: A Randomized, Controlled Clinical Trial
}

Bela E Toth $^{1^{*}}$, Istvan Takacs ${ }^{2}$, Laszlo Szekeres ${ }^{3}$, Boglarka Szabo ${ }^{2}$, Bence Bakos ${ }^{2}$ and Peter Lakatos ${ }^{2}$

${ }^{1}$ University of Debrecen, Faculty of Pharmacy, Department of Pharmaceutical Surveillance and Economy, Debrecen, Hungary

${ }^{2}$ Semmelweis University, Faculty of Medicine, 1st Department of Internal Medicine, Budapest, Hungary

${ }^{3}$ National Institute of Rheumatology and Physiotherapy, Budapest, Hungary

*Corresponding author: Bela E Toth, Department of Pharmaceutical Surveillance and Economy, University of Debrecen, Faculty of Pharmacy, Nagyerdei Krt. 98, Debrecen, 4032 Hungary, Tel: (36) 209429916; E-mail: tothe.bela@pharm.unideb.hu

Received date: July 05, 2017; Accepted date: August 03, 2017; Published date: August 10, 2017

Copyright: (c) 2017 Toth BE, et al. This is an open-access article distributed under the terms of the Creative Commons Attribution License, which permits unrestricted use, distribution, and reproduction in any medium, provided the original author and source are credited.

\section{Abstract}

Introduction: The primary objective of the study was to assess the safety and the efficacy of a "Slower Loading" dose of 30,000 IU vitamin D3 supplementation administered in a weekly schedule for 12 weeks in vitamin D deficient patients compared to the daily equivalent dose of $1000 \mathrm{IU} /$ day regimens in a clinical trial.

Methods: This open label, randomized, controlled, multicenter clinical trial was performed during the spring and summer period enrolling adult subjects with $25 \mathrm{OHD}$ levels $<20 \mathrm{ng} / \mathrm{ml}$. In a sub-study presented here, subjects were randomized into two treatment groups using 30,0000 IU Vitamin D3 film coated tablets either in weekly (WD30K group, daily dose equivalent of 4286 IU/day) or a standard dose for maintenance treatment in a daily administration (SDD1K group, $1000 \mathrm{IU} /$ day). Subjects in a control group received a similar 30,0000 IU Vitamin D3 film coated tablets in a once-per-month schedule (MD30K), dosing schedule for 12 weeks, (an equivalent to 1000 IU/day). The assessment of efficacy made by the changes in 25OHD and PTH levels in a throughout 12 weeks. Routine laboratory tests, serum and urinary calcium served for laboratory-safety assessments in every 4 weeks throughout the duration of the study.

Results: The baseline values of 25OHD at in group (WD30K, SDD1K and MD30K) were in similar range: $13.7 \pm$ $3.7 \mathrm{ng} / \mathrm{mL}, 13.48 \pm 3.9 \mathrm{ng} / \mathrm{mL}$ and $13.1 \pm 4.3 \mathrm{ng} / \mathrm{mL}$, respectively. A daily dose of $1000 \mathrm{IU}$ for 12 weeks was effective in restoration of $25 \mathrm{OHD}$ values to above $20 \mathrm{ng} / \mathrm{mL}(50 \mathrm{nmol} / \mathrm{L})$, however the median of the group failed to attain the $30 \mathrm{ng} / \mathrm{mL}(75 \mathrm{nmol} / \mathrm{L})$ threshold. Dose-response was statistically different in the 4286 IU/day group compared to a $1000 \mathrm{IU} /$ daily dose $(p<0.001)$ for all study visits. Treatment efficiency assessed on two levels and for treatment duration of 8 and 12 weeks. The limit of $25 \mathrm{ng} / \mathrm{mL}$ was achieved by $95 \%$ of patients in 8 weeks with 30,000 IU/wk administration (vs. only $33 \%$ with $1000 \mathrm{IU} / \mathrm{d}$ ) but more prominent difference observed with the limit of desired range ( $>30 \mathrm{ng} / \mathrm{ml}$ ): $91 \%$ vs. $10 \%$ of subjects in after 8 weeks with $30,000 \mathrm{lU} / \mathrm{wk}$ and $1000 \mathrm{lU} / \mathrm{d}$ doses and $95 \%$ vs. $24 \%$ by end of the 12 weeks of treatment. The treatment-related increment potential was in a range of 2.26-2.92 ng/week for the weekly $30 \mathrm{~K}$ dosing group compared to $1.32-1.70 \mathrm{ng} /$ week for the $1000 \mathrm{IU} / \mathrm{day}$ standard maintenance dose group after 8 weeks. Treatment with 30,000 IU doses of Vitamin D3 in a weekly administration for 12 weeks did not abolish serum calcium levels. No difference in frequency of laboratory adverse events and other safety parameters was observed compared to lower maintenance doses or to control group.

Conclusion: The safety of weekly loading oral doses of 30,000 IU vitamin D3 tablets was demonstrated and efficacy compared to the maintenance treatment with a daily dose equivalent of $1000 \mathrm{lU} / \mathrm{d}$, in a daily or in monthly schedule in vitamin D deficient, adult population. Weekly administration of 30,000 IU loading dose for 12 weeks does not raise safety concern, but provides an effective tool for normalization of $25 \mathrm{OHD}$ levels to the desirable level of $>30 \mathrm{ng} / \mathrm{mL}$ in deficient patients.

Keywords: Vitamin D; Hypovitaminosis; Dose-response curve; Clinical trials

\section{Introduction}

Epidemiological evidence on the high prevalence of relative or manifest hypovitaminosis $\mathrm{D}$ in the general healthy population have triggered a high interest in research and consequently the conclusions implicated that vitamin D has a potential role in the pathogenesis of several endocrine conditions, chronic diseases such as cancer, cardiovascular diseases, diabetes mellitus, male and female fertility, various autoimmune diseases, but also in chronic CNS disease conditions [1-7]. The maintenance of adequate 25 -hydroxy vitamin $\mathrm{D}$ (25OHD) levels in the blood is required since it is essential for a large number of physiologic mechanisms beyond the classic actions in calcium homeostasis. The new role of vitamin $\mathrm{D}$ as a pro-hormone is rather focusing on other areas and it is also widening range of therapeutic applications in prevention and maintenance of endocrine health $[7,8]$. 
Concentration of $25 \mathrm{OHD}$ is the biomarker used to determine vitamin $\mathrm{D}$ status. The various $25 \mathrm{OHD}$ thresholds of the recent years defining vitamin $\mathrm{D}$ adequacy may differ from the clinical practice referred by the Institute of Medicine (IOM) or from the recommendations of the Endocrine Society. It was concluded that optimal blood concentration of 25OHD should be above the limit of 30 $\mathrm{ng} / \mathrm{ml}(75 \mathrm{nmol} / \mathrm{L})[9,10]$.

Daily maintenance dosing of vitamin D3 in clinical practice often fails to achieve optimal outcomes, assessed by the level of 25OHD, compared to the recent dosing recommendations. Over the past decade the daily dosing targets have been elevated from $600 \mathrm{IU} / \mathrm{d}$ to 1500-2000 IU/d and considered blood 25OHD concentration as a clinically important surrogate outcome that correlates with health and disease [8-12].

On the other hand the biological half-life and the pharmacology of vitamin D indicate that it is suitable also for weekly or monthly dosing [13-16]. Moreover, the outcome of randomized clinical trial demonstrating the equal efficacy and safety of the dose equivalent of $1000 \mathrm{IU} /$ day administered either as daily $1000 \mathrm{IU}$, or once-in-a-week dose as of 7000 IU or once-in-a- month dose of 30,000 IU vitamin D3 tablets treatment in vitamin $\mathrm{D}$ deficient adult population was recently published by our research group [11] highlighting that 1000 IU daily equivalent dose for three months in vitamin $\mathrm{D}$ deficient population may elevate the mean $25 \mathrm{OHD}$ level above $20 \mathrm{ng} / \mathrm{ml}$, but a median of a treatment group cannot reach $30 \mathrm{ng} / \mathrm{ml}$. Previous studies have shown some effectiveness of low-dose supplementation lasting for winter period, but overall daily dose equivalents of $1000 \mathrm{IU}$ are considered as a minimally effective dose for the maintenance treatment of vitamin $\mathrm{D}$ deficiency [14-18]. Recent clinical trial data in elderly people supported the efficacy of $1500 \mathrm{IU} /$ day vitamin D in producing serum $25 \mathrm{OHD}$ serum concentrations higher than $30 \mathrm{ng} / \mathrm{ml}$ in a monthly or weekly dosing schedule [13].

A few recent studies reported the efficacy of an intermittent administration of high loading doses of 50,000-600,000 IU of vitamin D $[3,19]$, and confirmed the safety of loading dose with transient changes of plasma calcium levels and/or urinary calcium excretion only within a period of one month after dosing [19-21].

The potential safety concerns that a high intermittent weekly dosing of cholecalciferol might cause transient effects (i.e. hypercalcemia) because of the production of 1,25-dihydroxyvitamin $\mathrm{D}$, have been ruled out in a clinical report [13]. It was demonstrated in a clinical study that the administration of single 45,000 IU dose of vitamin D3 is not accompanied with hypercalcemia and even subsequent doses do not show statistically detectable but only a transient increase in $1,25(\mathrm{OH}) 2 \mathrm{D}$ in patients [13]. Lower doses do not expect to raise additional safety concerns; therefore a weekly $30,000 \mathrm{IU}$ dosing is potentially one suitable option for a Slower Loading treatment in deficient patients prior to maintenance.

The current clinical practices and treatment guidelines based on the National Osteoporosis Society's (NOS, UK) publication on treatment of vitamin $\mathrm{D}$ deficiency and also taken into consideration the available evidences and the development of consensus for patient management. For treatment, oral vitamin D3 is recommended with fixed loading doses followed by regular maintenance therapy when more rapid correction of vitamin D deficiency is required to achieve [22]. Loading regimens for treatment of deficiency may be scheduled as faster loading a total dose of approx. 300,000 IU within 5 days and aimed for treating hospitalized patients, while the schedule of slower loading is set for 6-7 weeks and it is recommended primarily for out-patients cases.

For safety monitoring, serum calcium should be checked one month after completing a loading regimen in case primary hyperparathyroidism has been unmasked. Although the dosing regimen is unlikely to result in any sign of toxicity, "It should be recognized" that certain groups may be at increased risk of this or adverse side effects (such as increased serum calcium) and they should be monitored [23].

The main objective of the present study was to demonstrate the comparative efficacy and safety of slower loading dose by a weekly administration of 30,000 IU vitamin D3 compared to the standard dose equivalent of $1000 \mathrm{IU} /$ day in vitamin D-deficient subjects.

\section{Materials and Methods}

\section{Study design and clinical sites}

This sub-study was designed as an open label, controlled, randomized multicenter clinical trial for adult subjects with vitamin $\mathrm{D}$ deficiency applying a weekly schedule of 30,000 IU vitamin D3 for 12 weeks. The clinical study was performed in Hungary with two clinical study centers, between February and October 2013. The study approval was granted by the Hungarian Central Ethics Committee (ETT-KFEB) and the competent regulatory authority (OGYI). The clinical study was registered on the www.clinicaltrials.gov (Reg. No.: NCT02069990) and EU Clinical Trials Register (EUDRACT: 2012-005232-29).

\section{Patients}

Subjects 18 years or older were recruited with vitamin D deficiency (defined as serum 25OHD levels were less than $20 \mathrm{ng} / \mathrm{ml}$ ) and considering all women with childbearing potential should be using oral contraceptives throughout the treatment period. The main exclusion criteria were: elevated serum Calcium (Ca) levels $(>2.60 \mathrm{mmol} / \mathrm{L}$ ); symptoms or anamnestic lab results of elevated $\mathrm{Ca}$ within a year or clinically significant signs of elevated urinary calcium excretion within two years prior to the study; chronic and severe grade of metabolic diseases or bone disorders; clinically significant malabsorption; obesity $\left(\mathrm{BMI}>35 \mathrm{~kg} / \mathrm{m}^{2}\right)$. The study related In/Ex criteria described in details elsewhere [11]. A permanent use of non-permitted medication or regular intake of vitamin D within 2 months prior to screening was not allowed for enrolment. Subjects with planned travels to areas of a high natural UVB exposition or a regular schedule for artificial UVB exposition (e.g. solarium) during the course of the study were also excluded. All participants provided written informed consent prior to participation. Blood and urine samples were collected then a physical examination and questionnaire on lifestyle and dietary calcium intake was completed on the screening visit to assess the daily average calcium consumption. All subjects enrolled were instructed to use sunblock lotion (factor 50+) over any intended UVB exposition during the study period.

\section{Dosing and study visit schedule}

After the screening and baseline blood and urine assessment, participants were randomly assigned, using a computer-generated block randomization schedule, to one of the dosing groups according to study dosing regimens. The WD30K group received $750 \mu \mathrm{g}(30,000$ IU) vitamin D3 film coated tablets in weekly schedule of 
administration (a total of 12 doses of 30,000 IU, for up to 12 weeks in total of 360,000 IU, a dose equivalent of $4285 \mathrm{IU} /$ day). The comparator dosing group (SDD1K) received standard doses of $1000 \mathrm{IU} /$ day film coated tablets for 90 days. The third group (MD30K) received the similar $750 \mu \mathrm{g}(30,000 \mathrm{IU})$ vitamin D3 film coated tablets and served as a "second" control group for this sub-study in monthly dosing schedule (a total of 3 doses of 30,000 IU to be taken on every 4 weeks, a total dose of 90,000 IU and similar equivalent dose of $1000 \mathrm{IU} /$ day) for the span of 12 weeks. All subjects in treatment groups were following the given dose regimens for 3 month, with interim visits scheduled in every 30 days ( \pm 8 days) to assess the safety and the efficacy of the treatment. Upon the serum levels of reached or above $32 \mathrm{ng} / \mathrm{ml}$ limit in any of the interim visits the subject continued with a dose equivalent of $1000 \mathrm{IU} /$ day until the end of the study.

Investigational medicinal product and study materials: Investigational Medicinal Products (IMP) in use in this sub-study were 30,000 IU and 1000 IU vitamin D3 these are yellow colored, round, film coated tablets with the active ingredient of cholecalciferol (either $1000 \mathrm{IU}$ or 30,000 IU vitamin D3. All batches of IMP for the clinical trial were manufactured, specified and controlled in composition and quality as described earlier [11]. Additional to IMP a supplementation of $400-600$ or $800 \mathrm{mg}$ calcium in form of calcium citrate tablets (Citrokalcium $200 \mathrm{mg}$ tablets, Reg.: OGYI-T-7260; MAH: Pharma Patent Ltd., Hungary) were supplied to all subjects who claimed to be deficient in daily calcium intake, assessed by a calcium-intake questionnaire.

\section{Laboratory tests}

On screening and on each study visits (on every 30 days) blood and urine samples were collected to determine study-specific lab parameters, including 25OHD, parathyroid hormone (PTH), serum calcium as well as routine chemistry (included standard blood biochemistry included ALT, ASP, GGT, ALP, LDH, serum creatinine, urea, glucose, cholesterol, triglyceride) and urine tests. The tests were repeated on the final visit at day 90 ( \pm 8 days). The measurement of 25OHD and PTH was carried out by a direct, competitive chemiluminescence, fully-automated immunoassay (CLIA, LIAISON analyzer DiaSorin, USA). The intra- and inter-assay coefficients of variances $(\mathrm{CV})$ were $4.1-7.7 \%$ and $7.7 \%-10.9 \%$ respectively, at decreasing concentrations. The functional sensitivity was defined as the dose at which the $\mathrm{CV}=20 \%, 2.16 \mathrm{ng} / \mathrm{ml} \mathrm{t}-25 \mathrm{OHD}$. Serum calcium, phosphate, alkaline phosphatase, potassium, sodium, lactate dehydrogenase, creatinine, urea, glucose, cholesterol, triglyceride, aspartate aminotransferase, alanine-aminotransferase, gammaglutamyl transferase and urinary calcium, phosphate were measured with a Beckman-Coulter automatic chemistry analyzer Au5800 (Beckman Coulter, Brea, USA). Urinary calcium excretion was assessed as a ratio of urinary calcium to creatinine concentrations [24].

\section{Statistical analysis}

The primary aim of the present study was to analyze serum 25OHD levels of subjects randomly assigned to treatment (WD30K) and comparator groups (SDD1K, MD30K) defined by the schedule of vitamin D3. These measurements were conducted at baseline and at the conclusion of the study. Power calculation was carried out to estimate the power of a one-way ANCOVA model with Dunnett post hoc test or T-test for test for pairwise comparisons. A sample size of 20 per treatment group was planned with the power estimation carried out by simulating and analyzing 5000 series of data. The power of the tests for the different hypotheses set up for each pairwise comparison was estimated based on these analyses. The estimated power was greater than $80 \%$ for comparisons WD30K vs. SDD1K. The overall type-I error of Dunnett-tests is considered as $<5 \%$, for each of the tests hypothesis, independently.

Descriptive demographic statistics and assessment on safety parameters (serum and urine $\mathrm{Ca}, \mathrm{PTH}$ ) by the frequency and distribution of adverse events were conducted by KolmogorovSmirnov and Levene statistical tests. The efficacy of vitamin D3 supplementation was determined by using Analysis of Covariance (ANCOVA) between the study groups. Incremental treatment potential assessed by change in serum 25OHD from baseline levels divided by the treatment duration in weeks. Treatment efficacy for each group was calculated and normalized by the mean of $25 \mathrm{OHD}$ elevation relative to the baseline values within the same treatment group:

$$
\text { [Effn } \left.(\mathrm{dx})=\left(25 \mathrm{OHD}(\mathrm{dx})-25 \mathrm{OHD} \mathrm{B}_{\text {Baseline }}\right) / 25 \mathrm{OHD} \text { Baseline }\right]
$$

Where 25OHD $(\mathrm{dx})$ is the nominal value of serum 25OHD levels at day $\mathrm{x}$ of treatment, 25OHD Baseline refers to nominal value of $25 \mathrm{OHD}$ at baseline.

Each EDC data point was collected by and analyzed using the clinical database software (Mythos system by Adware Research Ltd, Hungary). After the CDC, Statistical analyses were accomplished using SPSS 19 (IBM Corporation, New York USA) and SAS 9.3 (SAS Institute Inc. Cary, USA) as specified in statistical reports. All data management and statistical analyses were completed according to protocol validated by ISO 9100 standards and in line with ICH-GCP.

\section{Results}

A total of 140 subjects were screened and out of the 89 eligible cases 66 subjects ( 8 male/58 female) were enrolled to this sub-study according to study inclusion criteria, 22 randomized subjects to each treatment groups. All randomized subjects were Caucasian in race and residents in Hungary, the baseline demographic data are shown in Table 1.

Three patients dropped out with Withdraw of Consent $\left(\mathrm{W}_{\mathrm{O}} \mathrm{C}\right)$ and one subject was lost to follow-up; 62 completed per protocol this part of the sub-study. Rates of compliance were excellent in all study groups $(>95 \%)$, based on the number of tablets prescribed/collected unused medication. Data sets of each treatment groups were homogenous and in normal distribution. The duration of treatment varied in range of 84-90 days (for a weekly or a daily dosage groups) with a \pm 8 day window of visit allowance.

Serum 25OHD concentrations measured at baseline (group mean values) were in similar range for all three groups (WD30K: $13.70 \pm$ $3.69 \mathrm{ng} / \mathrm{mL}$, SDD1K:13.48 $\pm 3.86 \mathrm{ng} / \mathrm{mL}$ and MD30K:13.10 \pm 4.34 $\mathrm{ng} / \mathrm{mL}$ ) with no statistical differences. The treatment of vitamin $\mathrm{D}$ deficient subjects with $1000 \mathrm{IU} /$ daily dose equivalent on a daily or monthly treatment schedule are equally effective in elevation of $25 \mathrm{OHD}$ values to or above $20 \mathrm{ng} / \mathrm{ml}$, the dose-response is similar in the two groups and present similar efficacy by the end of the study as reported by our study group earlier [11]. 
Citation: Toth BE, Takacs I, Szekeres L, Szabo B, Bakos B, et al. (2017) Safety and Efficacy of Weekly 30,000 IU Vitamin D Supplementation as a Slower Loading Dose Administration Compared to a Daily Maintenance Schedule in Deficient Patients: A Randomized, Controlled Clinical Trial. J Pharmacovigil 5: 233. doi:10.4172/2329-6887.1000233

Page 4 of 10

\begin{tabular}{|c|c|c|c|c|c|c|c|}
\hline \multirow{2}{*}{ Treatment group and schedule } & \multirow{2}{*}{$\begin{array}{l}\text { Subjects } \\
\text { enrolled }\end{array}$} & \multirow{2}{*}{$\begin{array}{l}\text { Subjects drop } \\
\text { out }\end{array}$} & \multirow{2}{*}{$\begin{array}{l}\text { Subjects } \\
\text { completed }\end{array}$} & Age & Min & Max & Bodymass \\
\hline & & & & (years) & age & age & (kg) \\
\hline WD30K (weekly 30k IU) & 22 & 1 (WoC) & 21 & $57.50 \pm 16.48$ & 24 & 67 & $66 \pm 15.0$ \\
\hline SDD1K (daily 1000 IU) & 22 & 1 ( LFu) & 21 & $51.14 \pm 15.66$ & 26 & 75 & $77.1 \pm 14.9$ \\
\hline MD30K (monthly 30k IU) & 22 & 2 (WoC) & 20 & $55.67 \pm 17.54$ & 21 & 86 & $71.3 \pm 13.8$ \\
\hline
\end{tabular}

Table 1: Study demographics by treatment groups (WD30K: Weekly 30,000 IU vitamin D3 dosing; SDD1K: Daily 1000 IU dosing; MD30K: Monthly 30,000 IU vitamin D3 dosing; Values and standard deviation).

Nevertheless, by the end of treatment period only $11 / 22$ subject (50\%) were exceeded the level of $25 \mathrm{ng} / \mathrm{mL}$ and only $5 / 21$ subjects (24\%) could achieve the target level of $30 \mathrm{ng} / \mathrm{ml}$ with the standard daily 1000 IU dose, the mean $25 \mathrm{OHD}$ levels in these dose groups failed to attain the $30 \mathrm{ng} / \mathrm{mL}$ threshold. The restoration of $25 \mathrm{OHD}$ levels was more effective with a weekly 30,000 IU slower loading dose administration schedule: $91 \%$ and $95 \%$ of participants achieved complete normalization ( $>30 \mathrm{ng} / \mathrm{ml}$ ) during first 8 weeks or by the end of treatment period (12 weeks) (Table 2).

\begin{tabular}{|c|c|c|c|c|c|c|}
\hline \multirow{3}{*}{ Treatment daily dose } & \multicolumn{6}{|c|}{ Subjects in normal range (>30 ng/mL) } \\
\hline & \multicolumn{2}{|c|}{ week-4 } & \multicolumn{2}{|c|}{ week-8 } & \multicolumn{2}{|c|}{ week-12 } \\
\hline & ratio & $\%$ & ratio & $\%$ & ratio & $\%$ \\
\hline $4286 \mathrm{IU} / \mathrm{d}$ & $11 / 22$ & $50 \%$ & $20 / 22$ & $91 \%$ & $21 / 22^{*}$ & $95 \%$ \\
\hline $1000 \mathrm{IU} / \mathrm{d}$ & $0 / 22$ & $0 \%$ & $2 / 21$ & $10 \%$ & $5 / 21$ & $24 \%$ \\
\hline \multirow{3}{*}{ Treatment daily dose } & \multicolumn{6}{|c|}{ Subjects above $25 \mathrm{ng} / \mathrm{mL}$} \\
\hline & \multicolumn{2}{|c|}{ week-4 } & \multicolumn{2}{|c|}{ week-8 } & \multicolumn{2}{|c|}{ week-12 } \\
\hline & ratio & $\%$ & ratio & $\%$ & ratio & $\%$ \\
\hline $4286 \mathrm{IU} / \mathrm{d}$ & $16 / 22$ & $73 \%$ & $21 / 22$ & $95 \%$ & $21 / 22^{*}$ & $95 \%$ \\
\hline $1000 \mathrm{IU} / \mathrm{d}$ & $1 / 22$ & $5 \%$ & $7 / 21$ & $33 \%$ & $11 / 21$ & $95 \%$ \\
\hline
\end{tabular}

Table 2: Results of weekly dosing schedule of 4286 IU/d dose equivalent versus daily $1000 \mathrm{IU}$ vitamin D3 applied in reaching the targeted/normal range. (ratio: number of subjects above the limits of $30 \mathrm{ng} / \mathrm{mL}$, or $25 \mathrm{ng} / \mathrm{mL} 25 \mathrm{OHD}$ per total number of subjects each subgroup).

Efficacy assessed by the dose-response of blood 25OHD levels after 4- and 8-weeks of treatment. Slower loading dose administration (e.g. $4286 \mathrm{IU} /$ day in a WD30K group) resulted in significantly higher $(\mathrm{p}<0.5 \%)$ nominal values $(17.8 \pm 8.2$ and $22.52 \pm 6.8 \mathrm{ng} / \mathrm{mL})$, although the dose normalized values were $(4.16 \pm 1.92 ; 5.25 \pm 1.59$ for wk- 4 and wk-8 respectively), comparable to effect detected in control, (e.g. SDD1K group) with $1000 \mathrm{IU} /$ daily dose $(6.41 \pm 4.5 ; 10.59 \pm 5.6 \mathrm{ng} / \mathrm{mL})$ (Figure 1). ${ }^{*}$ One subject reached the level of $>30 \mathrm{ng} / \mathrm{mL}$ prior to DO.

The comparative utilization assessed in our study by the normalized treatment efficiency ratio $(\mathrm{Effn}(\mathrm{dx}))$ of the loading doses versus standard maintenance doses applied. The Effn $(\mathrm{dx})$ ratio calculated by the change of 25OHD from baseline within each treatment groups. The $30,000 \mathrm{IU} /$ wk loading dose schedule resulted in $\mathrm{Effn}(\mathrm{d} 56)=1.66$ after 8 weeks of treatment, that was at least two-times higher than that calculated for standard $1000 \mathrm{IU} /$ daily dose group $(\mathrm{Effn}(\mathrm{d} 56)=0.74)$.

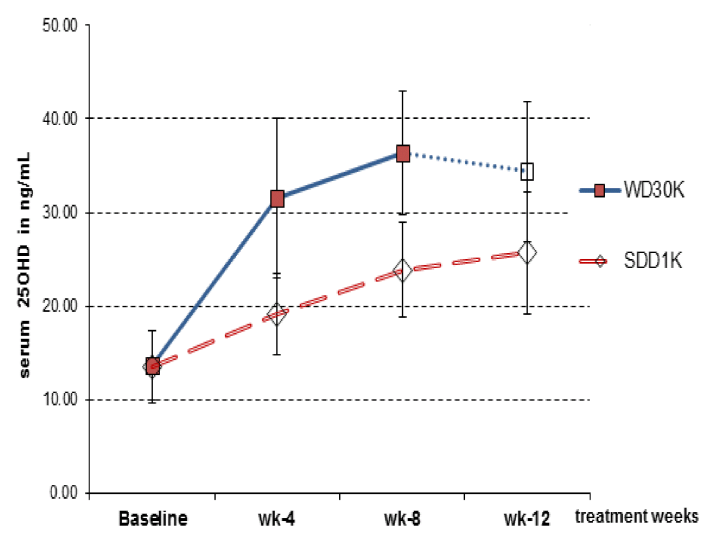

Figure 1: Effect of the daily equivalent dose of treatment efficacy by the changes of $25 \mathrm{OHD}$ levels. The WD30K group received weekly dosing of 30,000 IU vitamin D3 for 8 weeks (solid line, filled symbols). Upon reaching the $32 \mathrm{ng} / \mathrm{mL}$ limit subjects continued with $1000 \mathrm{IU} /$ day (dotted line, empty square). Dashed line with empty symbols (SDD1K) represents the daily maintenance dose of 1000 IU. Means and standard deviations represented.

The treatment-related increment potential has impact on treatment duration required to reach the desired level of 25OHD. The investigational Slower Loading dose regimens resulted in 2.26-2.92 $\mathrm{ng} / \mathrm{wk}$ increments for the first 8 weeks and dropped to $1.64-1.73 \mathrm{ng} / \mathrm{wk}$ for the span of 1-12 weeks. That is significantly higher in nominal values than that observed in $1000 \mathrm{IU} /$ day dose groups (1.32-1.70 $\mathrm{ng} / \mathrm{wk}$, and 1.02-1.31 ng/wk, respectively). The chart (Figure 2) is representing the treatment potential by the median increase on $25 \mathrm{OHD}$ levels during the 12-week-long study period. Most patients in Slower Loading dose group exceeded the limit of $32 \mathrm{ng} / \mathrm{ml}$ in 8 weeks (considered as "normal responders"), however a few patients from the same treatment group had markedly lower restoration speed of 25OHD levels resulted in a lower dose-response over the 12-week-long treatment period. Interestingly, these "slow responders" for whom the loading dose of $30,000 \mathrm{IU} / \mathrm{wk}$ group was just partially effective increasing $25 \mathrm{OHD}$ levels by the EOT, resulted in a low individual increment rate of $0.97-2.2 \mathrm{ng} /$ week. Similarly, in control group on standard maintenance doses of $1000 \mathrm{IU} / \mathrm{d}$, four patients had partially ineffective treatment result, based on a relatively low individual 
Citation: Toth BE, Takacs I, Szekeres L, Szabo B, Bakos B, et al. (2017) Safety and Efficacy of Weekly 30,000 IU Vitamin D Supplementation as a Slower Loading Dose Administration Compared to a Daily Maintenance Schedule in Deficient Patients: A Randomized, Controlled Clinical Trial. J Pharmacovigil 5: 233. doi:10.4172/2329-6887.1000233

Page 5 of 10

increment rate $(<0.70 \mathrm{ng} /$ week $)$. In these patients the given a total dose of 90,000 IU failed to restore the vitamin D deficiency to desirable level since the elevation observed was only in range of $0.07-4.7 \mathrm{ng} / \mathrm{mL}$ over the 12-week-long treatment period.

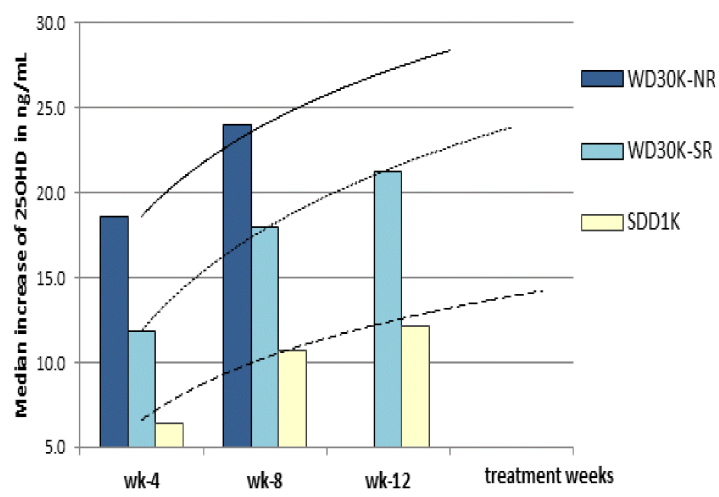

Figure 2: Treatment efficacy assessed by the median increase in serum 25OHD levels. Chart represents result stratified as normal responsers (WD30K-NR) and slow responders (WD30K-SR) to treatment by a loading dose with 30,000 IU/week vitamin D3. Light columns represents the control group (SDD1K) treated with 1000 IU/day. Logarythmic trendlines on 8 or 12 weeks of treatments are adjusted for prediction.
Serum PTH levels in the $1000 \mathrm{IU} / \mathrm{d}$ dose equivalent groups combined was $50.3 \pm 16.5 \mathrm{pg} / \mathrm{mL}$, versus $47.3 \pm 13.5 \mathrm{pg} / \mathrm{mL}$ for the $30,000 \mathrm{IU} / \mathrm{d}$ group at baseline, where $25 \%$ and $10 \%$ of patients had PTH levels >UNL, respectively. The 12-week-long treatment resulted in decrease in mean PTH for both groups, but statistically significant change $(-19.5 \%)$ for the higher dose (e.g. 4286 IU/day) was demonstrated $(\mathrm{p}<0.01)$, compared to $1000 \mathrm{IU} / \mathrm{d}$ group with $-9 \%$ of decrease $(\mathrm{p}=\mathrm{ns})$. Changes in PTH were more prominent in patients with lower baseline $25 \mathrm{OHD}$ levels (stratified as $<10 \mathrm{ng} / \mathrm{mL}$, vs. $10-20$ $\mathrm{ng} / \mathrm{mL}$ subgroups): the decrease from baseline was $-48 \%$, vs. $-18 \%$, for the weekly loading dose $(30,000 \mathrm{IU} / \mathrm{d})$ group compared to $-19 \%$, vs. $-3 \%$, for the maintenance dose equivalent (1000 IU/d) groups (Table 3).

Treatment-related changes in serum $\mathrm{Ca}$ and urinary $\mathrm{Ca}$ within in each dose groups and also differences between the treatment groups were evaluated. There was no relevant change detected in mean serum calcium within the study groups from baseline to end of treatment (EOT) visits and treatment related changes between the groups throughout the study (Table 4).

Safety assessment based on patient-reported Adverse Events (AE) and deviations of laboratory parameters included study specific and standard routine laboratory tests. Laboratory parameters deviating from normal range as exceeding the Upper Normal Range Limits (UNL) occurred during the study exposure considered in causality relationship to treatment related AE. Since urinary calcium levels may have transient higher levels during the day and the determination of 24-hour-collected urine for was not feasible to perform for this study, instead the calcium/creatinine ratio has been determined and was in use for evaluation.

\begin{tabular}{|l|l|l|l|l|l|l|}
\hline Dosing group & Variable & baseline & week-4 & week-8 & week-12 & p level" \\
\hline 4286 IU/d "WD30K" & Mean \pm STD & $47.3 \pm 13.5$ & $39.8 \pm 14.1$ & $42 \pm 14.4$ & $38 \pm 11.6$ & P<0.01 \\
\hline 1000 IU/d "SDD1K" & mean \pm STD & $48.2 \pm 14.6$ & $39.4 \pm 9.0$ & $44.4 \pm 17.0$ & $43.9 \pm 11.5$ & n.s. \\
\hline 1000 IU/d "MD30K" & mean \pm STD & $52.6 \pm 18.4$ & $39.8 \pm 16.8$ & $48.3 \pm 22.6$ & $48.4 \pm 20.8$ & n.s. \\
\hline "The significance levels assessed by the End of Treatment vs. Baseline & & & \\
\hline
\end{tabular}

Table 3: Changes in serum PTH (pg/mL) levels over the duration of the study by daily dose equivalent vitamin D3 (values are in pg/mL; STD: Standard deviation, p level: Significance levels assessed by the 25OHD levels on end of treatment visit at week 12 vs. Baseline, pairwise significance by T-test).

\begin{tabular}{|l|l|l|l|l|l|l|}
\hline \multirow{2}{*}{$\begin{array}{l}\text { Treatment } \\
\text { dose }\end{array}$} & Daily & \multicolumn{4}{|l|}{ Mean serum calcium (mmol/L) } \\
\cline { 2 - 7 } & Baseline & \multicolumn{2}{l|}{ EOT (wk-12) } & \multicolumn{2}{l|}{ Change } \\
\cline { 2 - 7 } & Value & STD & Value & STD & Value & $\%$ \\
\hline $4286 \mathrm{IU} / \mathrm{d}$ & 2.424 & \pm 0.09 & 2.431 & \pm 0.12 & -0.008 & $-0.30 \%$ \\
\hline $1000 \mathrm{IU} / \mathrm{d}$ & 2.366 & \pm 0.11 & 2.365 & \pm 0.09 & -0.001 & $0.00 \%$ \\
\hline
\end{tabular}

groups (i.e. from $4286 \mathrm{IU} / \mathrm{d}$, and $1000 \mathrm{IU} / \mathrm{d}$ ). The transient increase of serum calcium has been resolved to normal range by termination visit (EOT).

Deviation of urinary calcium levels and urinary calcium/creatinine ratio were considered as laboratory Adverse Event for the study. Four (4) subjects reported a total of 6 lab test cases of elevated urinary calcium levels and another three subjects reported 3 cases of elevated calcium/creatinine ratio, out of them two belonged to the $4286 \mathrm{IU} / \mathrm{d}$ group and the rest to control $1000 \mathrm{IU} / \mathrm{d}$ dosing. In a single (1) case of

Table 4: Changes in mean serum calcium levels by daily dose equivalent vitamin D3 (EOT: End of Treatment visit at week 12 vs. Baseline, prior dosing).

Only two individual cases reported slightly elevated serum calcium which did not exceed the $110 \%$ of UNL, both subjects received an 800 $\mathrm{mg}$ /day additional calcium supplementation, one of each treatment this latter group the increased urinary $\mathrm{Ca}$ level was detected during the EOT (termination) visit, all others were resolved prior to EOT. All patients reported elevated urinary calcium levels were received additional calcium supplementation throughout the study period and consequently a daily prescribed dose was reduced after deviation occurred. Overall there was no clinically significant difference in frequency of all $\mathrm{AE}$ between treatment groups were considered. 
Other lab-related deviations in haematology and serum biochemistry over UNL were subject to evaluation and the overall frequency of deviations was compared to baseline values. In one case from standard maintenance $(1000 \mathrm{IU} / \mathrm{d})$ group a lab-related $\mathrm{AE}$ reported in serum biochemistry on the EOT visit, where a mild increase of ALT, ASP, GGT, LDH were registered All other deviations occurred throughout the study were considered as clinically notsignificant or were existing also at baseline prior the study treatments.

There was no serious adverse event reported in the overall study period. No patient developed vitamin D toxicity. Two cases of nonlaboratory related AEs were reported, both were mild in intensity and recovered within the course of the study, none of them considered as treatment-related. No dropouts occurred due to adverse events.

\section{Discussion}

The outcome of the presented clinical investigation demonstrated that weekly 30,000 IU vitamin D3 dosing schedule for 8-12 weeks is a suitable option for loading deficient patients to reach the desirable limit of $30 \mathrm{ng} / \mathrm{ml}$. That is in accordance with the updated recommendations of the Endocrine Society concerned the optimal blood concentration of 25OHD [10]. Although there is "no universal consensus" on the limits for optimal levels and also an ongoing debate concerned the criteria for vitamin D deficiency, the weekly dosing regimen corresponds to the "Slower Loading" supplementation schedule published in 2013/14 in a practical clinical guideline on the management of vitamin D deficiency in adult patients by the National Osteoporosis Society (UK) [22,23]. The term "Slower Loading" corresponds to a suggested dosing schedule within the range of 20-50,000 IU/week for 6-7 weeks. According to guideline, when rapid correction of vitamin $\mathrm{D}$ deficiency is required the oral fixed loading doses of vitamin D3 are recommended approximately 300,000 IU in total, followed by a regular maintenance dose therapy in $800-2000$ IU/d given either daily or intermittently at higher cumulated doses $[22,23]$. On the other hand, the equal efficacy and safety of the daily oral dose equivalent of $1000 \mathrm{IU} /$ day, in daily or monthly (30,000 IU) dosing schedule is confirmed among vitamin $\mathrm{D}$ deficient adult population in our recent publication [11]. This report is also highlighting that the various (daily, weekly, monthly) regimens equivalent of $1000 \mathrm{IU} /$ daily maintenance dose are equally effective in restoration of $25 \mathrm{OHD}$ values to $>20 \mathrm{ng} / \mathrm{ml}$, however fail to attain 30 $\mathrm{ng} / \mathrm{mL}$ threshold even after 12 weeks [11] or in another study a similar dose after 24 weeks of treatment [25].

The results presented here was a sub-study of the above mentioned investigation, where the weekly 30,000 IU vitamin D3 loading dose applied for up to 12 weeks and confirmed the superiority in efficacy compared to daily standard maintenance dosing of $1000 \mathrm{IU} /$ day. This $30,000 \mathrm{IU} / w k$ schedule of "Slower Loading" dose administration provided $95 \%$ efficiency since all (except one) subjects were successful in restoration of deficiency to the desirable level $(>30 \mathrm{ng} / \mathrm{mL})$ in 8 weeks (group median: $35.2 \mathrm{ng} / \mathrm{mL}$ ). In contrast, only $14 \%$ of subjects from the $1000 \mathrm{IU} / \mathrm{d}$ group were able to reach the $30 \mathrm{ng} / \mathrm{mL}$ and only $41 \%$ were above the limit of $25 \mathrm{ng} / \mathrm{mL}$ with the group median of 24.1 $\mathrm{ng} / \mathrm{mL}$. Similar range of treatment efficacy of $1000 \mathrm{IU} / \mathrm{d}$ daily dose reported by Giusti et al. and also in a study of Schleck at al. when a total dose of 400,000 IU given (in combination of 50,000-200,000 IU loading doses in 8 weeks) resulting in $64 \%$ of subject reaching the target level of $30 \mathrm{mg} / \mathrm{mL}[25,26]$.
Interestingly, the same study group observed that a single high $(1 \times$ $300,000 \mathrm{IU})$ loading dose resulted in similar outcome of $25 \mathrm{OHD}$ restoration that observed with a daily dosing of $1000 \mathrm{IU}$, and more importantly that single high dose is overall less effective in restoration of vitamin D deficiency over 3 months. Moreover, only $55 \%$ of this high repeated dose (total of $600,000 \mathrm{IU}$ ) group reached desirable concentrations of $25 \mathrm{OHD}$, suggesting that even higher doses may be required for adequate vitamin D repletion [25].

A total amount of loading dose in our study was markedly less, $(12 \times 30,000 \mathrm{IU} / \mathrm{wk}=360,000 \mathrm{IU}$ in total) but provided a significantly better efficacy (95\%) in restoration of $25 \mathrm{OHD}$ to $>30 \mathrm{ng} / \mathrm{ml}$ levels for deficient patients. The discrepancies in outcome can only partially explained with a different baseline characteristics (age, mean 74.1 \pm 6.4 vs. $57.50 \pm 16.48$; baseline $25 \mathrm{OHD}$ : $9.4 \pm 5.1$ vs. $13.70 \pm 3.69$; proportion of severe deficiency $(<10 \mathrm{ng} / \mathrm{mL})$ of $60 \%$ vs. $25 \%$; and $\mathrm{In} / \mathrm{Ex}$ criteria: Postmenopausal vs. Healthy trial subjects) [25].

The calculated treatment-related increment potential of this applied $30,000 \mathrm{IU} /$ wk loading dose resulted in $2.26-2.92 \mathrm{ng} / \mathrm{wk} 25 \mathrm{OHD}$ mean increment for the first 8 weeks and followed by slightly diminished (by $27-41 \%)$ values for the span of 12 weeks (1.64-1.73 ng/week). The dose-response rate was in range as estimated, based on the Endocrine Society's Clinical Guidelines [10], and similar that was predicted by the Institute of Medicine [9]. Similar group mean $33.78 \pm 7.51 \mathrm{ng} / \mathrm{mL}$ $25 \mathrm{OHD}$ and range of increments are presented in a recent study in healthy adults; $2.48 \mathrm{ng} / \mathrm{wk}$ and $1.68 \mathrm{ng} / \mathrm{wk}$ for the span of 8 - or 12 weeks, respectively [26]. A decreasing increment potential (23-37\%) was observed also in our control groups (SDD1K, MD30K) resulted in figures of $1.32-1.70 \mathrm{ng} / \mathrm{wk}$, and $0.83-1.31 \mathrm{ng} / \mathrm{wk}$ by the 8 - or 12 -weeklong periods, respectively. That observation of decreasing efficacy over the time-course may have various explanations or the combination of these: (i) The increase in $25 \mathrm{OHD}$ correlates inversely with the actual serum $25 \mathrm{OHD}$ levels. The time-course and dose-response to daily or monthly oral vitamin D3 administration in healthy young volunteers has been discussed and reported earlier by several research groups $[13,27]$. It is observed that a response ratio is being reduced to almost half when initial 25OHD levels are above $20 \mathrm{ng} / \mathrm{mL}$ and decreasing proportionally in higher doses [3,28]. (ii) Higher doses may have slightly altered biological utilization and capacity to revert 25OHD levels, potentially due to $\mathrm{PK}$ reasons. A recent trial demonstrated that the dose-response curve of serum 25OHD concentration to cholecalciferol supplementation is widely variable, suggesting that people may respond differently, in terms of serum 25OHD increases, to a fixed dose of cholecalciferol $[25,29]$. Body mass or level of obesity (BMI) could be one of the parameters to consider when estimating the required dose of cholecalciferol. Although, obese subjects in general required more vitamin $\mathrm{D}$ supplementation than lean patients, there is a great variability in vitamin $\mathrm{D}$ response among subjects in the same replacement group, as noted elsewhere [25,30].

Previous observations support the recommendation that obese patients need more vitamin D3 than normal-weight patients to attain similar levels of 25OHD increase. The subjects enrolled for this study were from the general Hungarian population which is by statistics slightly overweight $(62.3 \% / \mathrm{male}$ and $48.9 \% /$ female, Eurostat data 2014). In that reason our study inclusion criteria were set for Body Mass Index (BMI) $<35$ of and generally, only the extremely obese subjects were excluded, however adjustment for subjects BMI $>30$ was not taken into account in dosing. It was observed that a few patients from each group showed markedly slower restoration capacity over the treatment period compared to normal responders. These "Slow 
Responders" for whom the loading dose was just partially effective due to low individual increment rate, in some cases probably due to higher BMI index or other dietary unknown reason. Since all participants in our study were Caucasians and residents in Hungary i.e. similar sun exposure, thus the UVB-transmission capacity of the skin of the trial subjects, as well as the potential "unintended" solar-exposure were considered similar. Since there was no statistically significant difference observed between subjects enrolled in early spring or summer period, probably due to the given instructions using UVBprotective lotions (provided to all participants) during intended sun exposure or outdoor activities, therefore the differences observed between individuals were less likely related to the level of UVBexposure. We understand that treatment related increase of $25 \mathrm{OHD}$ varies not only by external factors such as diet, exposure to sunlight, or also by internal ones, like the UVB transmission capacity of the skin or other genetic factors [31] but more importantly body (fat) composition [32]. The patient characteristics therefore may also influence the optimal vitamin D supplementation strategy.

This considered as one of the strengths of our study, since the recruitment of subjects was performed with a real range of BMI values of the population, including the lower end of obese range of BMI 30$35 \mathrm{~kg} / \mathrm{m}^{2}$. On the other hand, this may be considered as one of the weaknesses of the study, since the BMI data and dietary habits were in use only as exclusion criteria but not as a covariant for efficacy calculations. Nevertheless, our calculations on incremental efficacy are in line with the results reported by other research groups, assuming that deviation in BMI of the enrolled population would not be considered significant on the cumulative data. This fact however, also underlining the importance to assess the initial 25OHD prior to therapy due to concerns being ineffective dosing for those individuals who are outliers from the normal range either in these factors or having certain level of malabsorption.

Efficiency of the Slower Loading regimen was evaluated also by other two aspects: the incremental treatment potential and changes in PTH levels. The important point of this study is that a population who had proved hypovitaminosis D and consequently elevated or high PTH was therefore followed not only on 25OHD response to vitamin D supplementation, but also on the potential ability of different doses of cholecalciferol in normalize PTH levels. In clinical practice it is "commonly assumed" that elevated PTH or sHPTH is simply a matter of inadequate vitamin $\mathrm{D}$ intake that responds promptly to the supplementation of vitamin D [25]. In our study, the baseline mean PTH levels were in the upper normal range $(48.2-52.6 \mathrm{pg} / \mathrm{mL})$ in all groups, included the $10-25 \%$ of patients with slightly elevated values $>$ UNL. Despite the mean PTH was in (upper-) normal range at baseline it did decrease in all study groups with vitamin D supplementation, but the effect was statistically significant only for the weekly loading (30,000 IU) doses group and found more prominent for a subgroup with lower baseline 25OHD levels. Our results were in some aspects contrary to a statement that marked decrease of PTH is seen in both (oral cholecalciferol $1,000 \mathrm{IU} / \mathrm{d}$ or two doses of cholecalciferol 300,000 IU) groups over the 6 months follow-up period disrespectfully a significant difference in serum 25OHD response between the treatment groups [25]. In other studies published within the past years reported similar trends of serum PTH and 25OHD changes after different doses and regimens of cholecalciferol. Two trials in particular showed that, in people with vitamin D deficiency and sHPTH, a high loading dose of cholecalciferol produced a significantly more-rapid and -effective increase in serum 25OHD than a cumulative lower monthly or daily dose but a comparable decrease in PTH levels
$[3,33]$. The response of serum $25 \mathrm{OHD}$ to cholecalciferol is directly related to the cumulative dose of cholecalciferol, whereas PTH response to vitamin D supplementation is largely independent of the dose given. It is possible that, to some extent, PTH needs a longer period of time to respond to cholecalciferol, even when adequate serum 25OHD levels are reached and that the relationship between PTH decrease and 25OHD increase is not linear, as previously reported [34].

Another aspect of treatment safety is related to some recently published clinical studies with a concern about high annual doses of vitamin D that rapidly increases $25 \mathrm{OHD}$ and reducing PTH levels [35] and can be considered as potential risk. In fact, 500000 IU onceannual oral administration of high-dose cholecalciferol increases the risk of falls and fractures [36]. Administration in bolus exceeding 100,000 IU may be associated with acute increases of C-terminal telopeptides of type I collagen [37]. The weekly 30000 IU loading dose, applied in our study is well below these limits, therefore we did not monitor the frequency of falls and did not measure the changes of specific bone markers for the 12-week-long duration. On the other hand, the response to loading dose of vitamin D only attenuated elevated PTH levels to mid-range, but did not abolish it after 12 weeks of treatment.

\section{Safety Profile}

Due to long whole body half-life for vitamin D, daily dosing is generally considered unnecessary, therefore monthly or weekly dosing seems to be ideal solution. In our study, a loading dose of weekly 30,000 IU for 12 weeks in vitamin D deficient population was proven equally safe to standard daily maintenance dosing. Overall we did not find any difference in adverse event frequency among daily, weekly and monthly treatment schedule applied in this sub-study. In that aspect our data was in accordance with earlier data with a similar range [13] and also to recently published data on vitamin D3 supplementation with 50,000 IU twice weekly for 5 weeks is safe among patients with low 25OHD level [38].

Similar seamless safety profile characteristics of a loading dose reported by others applying regular administration of a daily, weekly and monthly dosing schedule, also for loading or combination of loading+monthly dosing of vitamin D3. A single loading doses of 100,000-500,000 IU, followed by a daily dose of $4800 \mathrm{IU}$ for 3 weeks (a total of $167,200 \mathrm{IU}$ ) or monthly doses of 50,000 IU for 8 months (a total of 900,000 IU in 9 month) do not result in safety issues in neither studies: no experience of hypercalciuria or hypercalcemia at any of the measured points are being detected. In general, the safety results in these studies within the referred dose ranges applied were good, serum calcium or urine calcium/creatinine levels do not differ in any these dosing groups and between-groups [3,13,39].

A theory that connects high levels of $25 \mathrm{OHD}$ facilitating the absorption of calcium from the GI tract may constitute hypercalcemia has been raised earlier as a potential safety concern. Recent publications pointed out that studies which in vitamin-D-deficient subjects, the loading dose is efficient in normalizing 25OHD do not result in serum calcium values above the reference range $[3,17,40]$. On the other hand, treatment with vitamin D3 is advised to prescribe with calcium supplements at doses between 400 and $800 \mathrm{mg}$ for calcium deficient subjects. Since the vast majority of the population is also deficient in dietary calcium, it was considered to assess the level deficiency. In the present study all enrolled subject received 800 
$\mathrm{mg} /$ day calcium (in form of calcium-citrate) unless the Ca-intake questionnaire resulted in sufficient dietary calcium intake at baseline. That point was considered weakness and a potential error in our study, since dietary calcium intake may have changed during the course of the study resulted in potential unintended overload of calcium, and increase of urinary concentration. vitamin D repletion itself in general does not alter urinary calcium excretion, despite increased calcium absorption. Since calcium excretion did not change after vitamin D therapy applied supplementation can be provided also to postmenopausal women who are not stone-formers and who are vitamin $\mathrm{D}$ insufficient, without fear of increased risk of nephrolithiasis [41].

Our study has certain limitations. First, the number of participants was small compared to the number of study groups; however, the study has sufficient statistical power as it was calculated in advance.

Another potential limitation of the study design is the question of placebo controlled double blinded manner. Although blinding was not necessary because all patients received the active agent and the outcome of the experimental design, i.e., serum 25OHD and PTH levels could not have been modified through a placebo effect. Using placebo could have been achieved by administering placebo tablets, but it was not neither necessary, since the efficacy of maintenance doses have been well established, and treating patients with severe deficiency would have introduced another level of ethical issue and unnecessary complexity.

Pharmacokinetic assessment during the first days immediately after the dose administrations could have been potentially elaborated more by the aspects of vigilance on short-term safety parameters. On the other hand, assessing any of the potential transient or harmful effects of the weekly doses was not necessary since the kinetics and the shortterm safety of vitamin D supplementation of single oral doses of $50,000-500,000 \mathrm{IU}$ have been evaluated in multiple trials without any of safety concerns $[20,42,43]$ and their results were confirmed recently $[38,44]$ and dosing in our study we were below of that range. Also it is less likely that any population of non-Caucasian races (residents with darker skin e.g. Africans, Indians, etc. who otherwise high of suffering from vitamin D deficiency) would have any impact on safety of loading doses since the additive effect of solar UVB-exposure is considered even less significant during the treatments and afterwards.

Finally, the relatively short 12 -week-long study period is considered another limitation. Longer study duration and treatment would have produced higher $25 \mathrm{OHD}$ levels by the final assessment, but that was in range with the clinical guidelines and recommendation for loading dose administration. Earlier time points within this study (i.e., at week 4 and 8 ), the relative $25 \mathrm{OHD}$ increase already resulted in statistically significant contrasts between the weekly and daily dosing groups and that remained unchanged by end of treatment.

The study design as a prospective, controlled, randomized, multicenter clinical trial is the main advantage of our study. Moreover, we used a novel loading dose schedule of vitamin D3 doses in forms of oral tablets available for public and suitable for ambulatory patients, as opposed to a specialized (non-commercial) vitamin D ethanol solution in other studies referred. Moreover, as a comparator the daily equivalent dose was in use here, since $1000 \mathrm{IU}$ is considered a safe and minimally effective dose for maintenance treatment of vitamin D deficiency [18]. Strength of the study is the comprehensive assessment of efficacy and safety not just during the low UVB season (i.e., winter and spring) but also in in real-life summer conditions in otherwise vitamin $\mathrm{D}$ deficient, healthy adult population. It should be noted that the effect of vitamin D3 replacement on serum 25OHD levels did not show major seasonal fluctuations, presumably due to the general instructions from dermatologists using sunscreen lotion during periods of normal-to-high potential UVB exposures.

\section{Conclusion}

In summary, the efficiency of the weekly loading dose regimen of $30,000 \mathrm{IU} /$ wk to reach desirable optimal (>30 ng/mL) levels of $25 \mathrm{OHD}$ is safe and reliable. Compared to standard dose equivalents of 1000 $\mathrm{IU} / \mathrm{d}$ due to a decreased incremental capacity above the $25 \mathrm{ng} / \mathrm{ml}$ the $25 \mathrm{OHD}$ levels are reaching its plateau and the maintenance treatment seems to be relatively ineffective for the desirable further increase.

Our data also shown, that there is a certain value in obtaining a 25OHD level in a clinical setting to monitor the 25OHD response to vitamin D supplementation for a specific population since individual's response to a given dose of cholecalciferol is potentially variable. There was no new safety concern identified during the administration of this loading dose regimen. There was no change in assessments of other potential safety concerns based on previous safety results such as overdosing, risks of abolished serum calcium level or hypercalciuria. Here should be noted that safety concerns associated with the active ingredient cholecalciferol component in a form of a 30,000 IU product do not qualify as important risks according to the criteria in GVP Module V.

In conclusion, our study demonstrated the safety and a predictable efficacy profile of a weekly loading dose of 30,000 IU vitamin D3 tablets normalizing the vitamin D deficiency.

Daily dose equivalents of $1000 \mathrm{IU} / \mathrm{d}$, either in a daily $1000 \mathrm{IU}$ or in a monthly dosing of 30,000 IU schedules for 12 weeks of treatments failed to attain the $30 \mathrm{ng} / \mathrm{mL}$ threshold. Weekly administration of this loading dose for 12 weeks does not raise safety concern, but proved to be an effective tool to reach the $>30 \mathrm{ng} / \mathrm{mL}$ limits in deficient patients.

\section{Conflict of Interest}

This work was supported by Pharma Patent Kft. There are no other organizations with any financial interest in the subject matter or material discussed in the manuscript. Laszlo Szekeres, Boglarka Szabo, Bence Bakos have nothing to declare. Bela E Toth consulted for Pharma Patent Kft. Peter Lakatos and Istvan Takacs received lecture fees from Pharma Patent Kft.

\section{Acknowledgements}

The authors are sincerely grateful to Stephanie C. Fox, J.D. of Queen Bee Edit of Bloomfield Connecticut, U.S.A. for her technical assistance in language improvement of the manuscript.

\section{References}

1. Petho Z, Kulcsar-Jakab E, Kalina E, Balogh A, Pusztai A, et al. (2015) Vitamin D status in men with psoriatic arthritis: acase-control study. Osteoporos Int 26: 1965-1970.

2. Nagpal S, Na S, Rathnachalam R (2005) Noncalcemic actions of vitamin D receptor ligands. Endocr Rev 26: 662-687.

3. Bacon CJ, Gamble GD, Horne AM, Scott MA, Reid IR (2009) High-dose oral vitamin D3 supplementation in the elderly. Osteoporos Int 20: 1407-1415. 
Citation: Toth BE, Takacs I, Szekeres L, Szabo B, Bakos B, et al. (2017) Safety and Efficacy of Weekly 30,000 IU Vitamin D Supplementation as a Slower Loading Dose Administration Compared to a Daily Maintenance Schedule in Deficient Patients: A Randomized, Controlled Clinical Trial. J Pharmacovigil 5: 233. doi:10.4172/2329-6887.1000233

Page 9 of 10

4. Devaraj S, Yun JM, Duncan-Staley CR, Jialal I (2011) Low vitamin D levels correlate with the proinflammatory state in type 1 diabetic subjects with and without microvascular complications. Am J Clin Pathol 135: 429-433.

5. Cantorna MT, Mahon BD (2004) Mounting evidence for vitamin D as an environmental factor affecting autoimmune disease prevalence. Exp Biol Med (Maywood) 229: 1136-1142.

6. Davidson MB, Duran P, Lee ML, Friedman TC (2013) High-dose vitamin $\mathrm{D}$ supplementation in people with prediabetes and hypovitaminosis D Diabetes Care 36: 260-266.

7. Muscogiuri G, Mitri J, Mathieu C, Badenhoop K, Tamer G, et al. (2014) Mechanisms in endocrinology: vitamin $\mathrm{D}$ as a potential contributor in endocrine health and disease. Eur J Endocrinol 171: R101-110.

8. Muscogiuri G, Altieri B, Annweiler C, Balercia G, Pal HB, et al. (2017) Vitamin D and chronic diseases: the current state of the art. Arch Toxicol 91: 97-107.

9. Ross AC, Manson JE, Abrams SA, Aloia JF, Brannon PM, et al. (2011) The 2011 report on dietary reference intakes for calcium and vitamin D from the Institute of Medicine: what clinicians need to know. J Clin Endocrinol Metab 96: 53-58.

10. Holick MF, Binkley NC, Bischoff-Ferrari HA, Gordon CM, Hanley DA, et al. (2011) Evaluation, treatment, and prevention of vitamin D deficiency: an Endocrine Society clinical practice guideline. J Clin Endocrinol Metab 96: 1911-1930.

11. Takacs I, Toth BE, Szekeres L, Szabo B, Bakos B et al. (2017) Randomized clinical trial to comparing efficacy of daily, weekly and monthly administration of vitamin D (3). Endocrine 55: 60-65.

12. Takacs I, Benko I, Toldy E, Wikonkal N, Szekeres L, et al. (2012) Hungarian Consensus about the vitamin $\mathrm{D}$ effects on prevention and treatment of diseases. Orv Hetil 153: 5-26.

13. Ish-Shalom S, Segal E, Salganik T, Raz B, Bromberg IL, et al. (2008) Comparison of daily, weekly, and monthly vitamin D3 in ethanol dosing protocols for two months in elderly hip fracture patients. Clin Endocrinol Metab 93: 3430-3435.

14. Vieth R (2005) The pharmacology of vitamin D, including fortification strategies.In: Feldman D, Glorieux F, Pike JW, Vitamin D. New York: Elsevier, 995-1015.

15. Ilahi M, Armas LA, Heaney RP (2008) Pharmacokinetics of a single, large dose of cholecalciferol. Am J Clin Nutr 87:688-691.

16. Lawson DE, Douglas J, Lean M, Sedrani S (1986) Estimation of vitamin D3 and 25-hydroxyvitamin D3 in muscle and adipose tissue of rats and man. Clin Chim Acta 157: 175-181.

17. Vieth R, Chan PC, MacFarlane GD (2001) Efficacy and safety of vitamin D3 intake exceeding the lowest observed adverse effect level. Am J Clin Nutr 73:288-294.

18. Szabo B, Tabak AG, Toldy E, Szekeres L, Szili B, et al. (2017) The role of serum total and free 25-hydroxyvitamin D and PTH values in defining vitamin $\mathrm{D}$ status at the end of winter: a representative survey. J Bone Miner Metab 35: 83-90.

19. Cipriani C, Romagnoli E, Scillatani A, Chiodini I, Clerico R, et al. (2010) Effect of a single oral dose of 600,000 IU of cholecalciferol in serum calciotropic hormones in young subjects with vitamin D deficiency: A prospective intervention study. J Clin Endocrinol Metab 95: 4771-4777.

20. Romagnoli E, Mascia ML, Cipriani C, Fassino V, Mazzei F, et al. (2008) Short and long-term variations in serum calciotropic hormones after a single very large dose of ergocalciferol (vitamin D2) or cholecalciferol (vitamin D3) in the elderly. J Clin Endocrinol Metab 93: 3015-3020.

21. Amrein K, Sourij H, Wagner G, Holl A, Pieber TR, et al. (2011) Short term effects of high dose oral vitamin D3 in critically ill vitamin D deficient patients: a randomized, double blind, placebo controlled pilot study. Crit Care 15: R104.

22. Aspray TJ, Bowring C, Fraser W, Gittoes N, Javaid MK, et al. (2014) National Osteoporosis Society vitamin D guideline summary. Age Ageing 43: 592-595
23. Francis R, Aspray T, Fraser W, Gittoes N, Javaid K, et al. (2013) Vitamin D and Bone Health: A Practical Clinical Guideline for Patient Management. National Osteoporosis Society.

24. Gokce C, Gokce O, Baydinc C, Ilhan N, Alasehirli E, et al. (1991) Use of random urine samples to estimate total urinary calcium and phosphate excretion. Arch Intern Med 151: 1587-1588.

25. Giusti A, Barone A, Pioli G, Girasole G, Razzano M, et al. (2010) Heterogeneity in serum 25-hydroxy-vitamin D response to cholecalciferol in elderly women with secondary hyperparathyroidism and vitamin D deficiency. J Am Geriatr Soc 58: 1489-1495.

26. Schleck ML, Souberbielle JC, Jandrain B, Da Silva S, De Niet S, et al. (2015) A Randomized, Double-Blind, Parallel Study to Evaluate the DoseResponse of Three Different Vitamin D Treatment Schemes on the 25Hydroxyvitamin D Serum Concentration in Patients with Vitamin D Deficiency. Nutrients 7: 5413-5422.

27. Heaney RP, Davies KM, Chen TC, Holick MF, Barger-Lux MJ (2003) Human serum 25-hydroxycholecalciferol response to extended oral dosing with cholecalciferol. Am J Clin Nutr 77: 204-210.

28. Viljakainen HT, Palssa A, Kärkkäinen M, Jakobsen J, Lamberg-Allardt C (2006) How much vitamin D3 do the elderly need? J Am Coll Nutr 25: 429-435.

29. Aloia JF, Patel M, Dimaano R, Li-Ng M, Talwar SA, et al. (2008) Vitamin $\mathrm{D}$ intake to attain a desired serum 25-hydroxyvitamin $\mathrm{D}$ concentration. Am J Clin Nutr 87: 1952-1958.

30. Drincic A, Fuller E, Heaney RP, Armas LA (2013) 25-Hydroxyvitamin D response to graded vitamin D3 supplementation among obese adults. J Clin Endocrinol Metab 98: 4845-4851.

31. Wang TJ, Zhang F, Richards JB, Kestenbaum B, van Meurs JB, et al. (2010) Common genetic determinants of vitamin $\mathrm{D}$ insufficiency: a genomewide association study. Lancet 376: 180-188.

32. Grethen E, McClintock R, Gupta CE, Jones R, Cacucci BM, et al. (2011) Vitamin D and hyperparathyroidism in obesity. J Clin Endocrinol Metab 96:1320-1326.

33. Premaor MO, Scalco R, Da Silva MJ, Froehlich PE, Furlanetto TW (2008) The effect of a single dose versus a daily dose of cholecalciferol on the serum 25-hydroxycholecalciferol and parathyroid hormone levels in the elderly with secondary hyperparathyroidism living in a low-income housing unit. J Bone Miner Metab 26: 603-608.

34. Yendt ER, Kovacs KA, Jones G (2008) Secondary hyperparathyroidism in primary osteoporosis and osteopenia: Optimizing calcium and vitamin D intakes to levels recommended by expert panels may not be sufficient for correction. Clin Endocrinol (Oxf) 69: 855-863.

35. Pepe J, Mezzaroma I, Fantauzzi A, Falciano M, Salotti A, et al. (2016) An oral high dose of cholecalciferol restores vitamin $\mathrm{D}$ status in deficient postmenopausal HIV-1-infected women independently of protease inhibitors therapy: a pilot study. Endocrine 53: 299-304.

36. Sanders KM, Stuart AL, Williamson EJ, Simpson JA, Kotowicz MA, et al. (2010) Annual high-dose oral vitamin D and falls and fractures in older women: a randomized controlled trial. JAMA 303: 1815-1822.

37. Rossini M, Adami S, Viapiana O, Fracassi E, Idolazzi L, et al. (2012) Dosedependent short-term effects of single high doses of oral vitamin D3 on bone turnover markers. Calcified Tissue International 91: 365-369.

38. Shieh A, Chun RF, Ma C, Witzel S, Meyer B, et al. (2016) Effects of HighDose Vitamin D2 Versus D3 on Total and Free 25-Hydroxyvitamin D and Markers of Calcium Balance. J Clin Endocrinol Metab 101: 3070-3078.

39. Oliveri B, Mastaglia SR, Brito GM, Seijo M, Keller GA, et al. (2015) Vitamin D3 seems more appropriate than D2 to sustain adequate levels of 25OHD: a pharmacokinetic approach. Eur J Clin Nutr 69: 697-702.

40. Vieth R (2006) Critique of the considerations for establishing the tolerable upper intake level for vitamin D: critical need for revision upwards. J Nutr 136: 1117-1122.

41. Penniston KL, Jones AN, Nakada SY, Hansen KE (2009) Vitamin D repletion does not alter urinary calcium excretion in healthy postmenopausal women. BJU Int 104: 1512-1516. 
Citation: Toth BE, Takacs I, Szekeres L, Szabo B, Bakos B, et al. (2017) Safety and Efficacy of Weekly 30,000 IU Vitamin D Supplementation as a Slower Loading Dose Administration Compared to a Daily Maintenance Schedule in Deficient Patients: A Randomized, Controlled Clinical Trial. J Pharmacovigil 5: 233. doi:10.4172/2329-6887.1000233

Page 10 of 10

42. Rossini M, Gatti D, Viapiana O, Fracassi E, Idolazzi L, et al. (2012) Shortterm effects on bone turnover markers of a single high dose of oral vitamin D3. J Clin Endocrinol Metab 97: E622-E626.

43. Courbebaisse M, Thervet E, Souberbielle JC, Zuber J, Eladari D, et al. (2009) Effects of vitamin D supplementation on the calcium-phosphate balance in renal transplant patients. Kidney Int 75: 646-651.
44. Benaboud S, Urien S, Thervet E, Prie D, Legendre C, et al. (2013) Determination of optimal cholecalciferol treatment in renal transplant recipients using a population pharmacokinetic approach. Eur J Clin Pharmacol 69: 499-506. 